and veterinary surgeons-constituting $15 \%$ of the total number of known addicts. According to the report sent to the United Nations from the United Kingdom doctors made up $81 \%$ of all the known "professional addicts," including nurses. As always where drug abuse is concerned, the number of officially known addicts is almost certainly a much lower figure than the real situation would disclose. M. F. A'Brook and his colleagues ${ }^{2}$ had among their 192 patients 30 who were addicted to some drug other than alcohol.

In Germany ${ }^{9}$ there were in 19574,861 addicts, of whom $12 \%$ were doctors. One doctor in 112 was an addict. Reports from the United States deal for the most part with selected populations of doctors - those treated in private ${ }^{10}$ or in the special hospital for addicts at Lexington, Kentucky. ${ }^{11}$ Many psychopathological explanations of the development of addiction in these doctors have emerged from the intensive study they received, but there can be little doubt that the most potent factor in giving them an unhappy pre-eminence among addicts has been the easy access to drugs (though this is not of course the only important factor). It is noteworthy in this connexion that in a study by J. L. Evans ${ }^{12}$ of 50 doctors' wives who received treatment in a private psychiatric hospital between 1960 and 196310 had overuse of drugs as their major presenting symptom, and 12 others had a history of overuse of addictive drugs (apart from alcohol). Fourteen of these 22 women had used morphine or morphine derivatives. Evans concludes that the addiction was related "dynamically and empirically to the profession of the husbands." A number of the women had continued to have ready access to drugs after the addiction was evident.

Can nothing be done to reduce the numbers of doctors' lives wasted by these occupational hazards? Too often, perhaps, colleagues who are aware that all is not well stand aside and refuse to interfere when early action is essential.

\section{Arthritis and Sarcoidosis}

Sarcoidosis is a widespread granulomatous process the signature of which is the sarcoid nodule. This is demonstrable by biopsy and sufficiently characteristic and uniform under the microscope to imply that sarcoidosis has a single cause, but the occurrence of an identical sarcoid reaction to beryllium disease and to some fungal infections proves otherwise. Beryllium disease and fungus infections of this type, however, are rare, and sarcoidosis without exposure to these agents is fairly common, so experts in the disease may be forgiven if they continue to write about sarcoidosis and not about the "sarcoidoses." This apparently academic point is of practical importance in assessment of the prognosis of the condition and its associated manifestations such as arthritis.

A variety of quite different joint conditions have been described as associated with sarcoidosis. The value of studies of this kind is limited if several types of sarcoidosis are lumped together in the reported series. This is particularly so when the Kveim reaction (an artificially induced local sarcoid nodule) is used as proof of the disease. Statistics based on hospital studies are notoriously fallible when it comes to describing apparent association between diseases whose causes are unknown. The "two-disease fallacy" creeps in-the interesting possessor of two diseases is far more likely to be written about than the humdrum patient with only one. Epidemiological studies might be expected to help to clarify the association between arthritis and sarcoidosis, and a valuable survey has been reported by I. Sutherland, D. N.
Mitchell, and P. D'A. Hart, who looked for the development of sarcoidosis in a 14-year prospective follow-up study of 54,239 children and adolescents vaccinated against tuberculosis or observed as unvaccinated controls. They found 52 cases and mentioned that only three of them had joint pains. Nevertheless, workers in hospitals continue to find a high incidence of arthritis in histologically proved sarcoidosis, and in some patients this may be the presenting complaint.

The problem has been looked at both in rheumatism clinics (where the selection factor for arthritis is to be expected, and in specialized sarcoidosis clinics, as in a recent study by J. M. Gumpel and his colleagues. ${ }^{2}$ If nonspecific or unrelated causes of joint symptoms are excluded at least three different presentations of arthritis emerge. The first, wellcharacterized, is an acute arthritis predominantly of the knees and ankles, occurring with or often before erythema nodosum The characteristic patient is in the third or fourth decade and is more often a woman, and the associated clinical features include a painful oedema of the ankles and feet, marked and sometimes incapacitating stiffness of the limbsespecially in the mornings-fever, enlarged hilar lymph nodes, and general malaise. The response of the arthritis to corticosteroids is excellent and complete recovery is the rule, at least in Britain. Anergy to tuberculin and biopsy evidence of sarcoidosis in lymph nodes or other tissues in a small proportion of cases has led to this condition being classified as an arthritis of sarcoidosis, but neither the sarcoidosis nor the arthritis leaves any permanent residue. A positive Kveim test is common and by itself has been accepted as histological proof of sarcoidosis-for example, by Dr. D. G. James and his associates. ${ }^{3}$ Sutherland and his colleagues, however, thought that the Kveim positivity had "some immunological basis not directly related to sarcoidosis." In other words, the presence of a positive Kveim test by itself should not be taken as histological proof of sarcoidosis. Many would feel that it would be preferable to regard this acute, early, and clinically distinct form of arthritis as no more than a part of the "erythema nodosum syndrome" and, as L. H. Truelove $e^{4}$ suggested, " as independent of the underlying cause of the syndrome, whether this be sarcoidosis, tuberculosis, or drug sensitivity."

Two other forms of arthritis associated with sarcoidosis reflect the granulomatous invasion of the para-articular bone or of the synovium. They are much less common, much more likely to become chronic, and they are always associated with clinically apparent granuloma formation in the skin, lung parenchyma, eyes, lymph nodes, or peripheral nerves. Sarcoid dactylitis may give swollen painful fingers, which resemble rheumatoid arthritis superficially, but the radiograph will show the diffuse osteitis in the phalanges-3n appearance which is seen much more frequently than the often quoted punched-out cysts. Synovial lesions ${ }^{\text {s }}$ may take the form of localized plaques of sarcoid-containing tissue, which replace part of the synovium and are associated with a nonspecific reaction elsewhere in the joints. The clinical course of such lesions is variable but usually takes the form of a subacute and recurrent hydrarthrosis. Both the arthritis

\footnotetext{
Sutherland, I., Mitchell, D. N., and Hart, P. D'A., Brit. med. F., 1965

2 Gumpel. J. M., Johns, C. J., and Shulman, L. E., Ann. rheum. Dis. $1967,26,194$

3ames, D. G., Thomson, A. D., and Willcox, A., Lancet, 1956, 2, 218

Truelove, L. H., Ann. rheum 'Dis.. 1960, 19, 174.

- Bianchi, F. A., and Keech, M. K., ibid., 1964, 23, 463.

- Bonnet, W. L., Radiology, 1946, 47, 175.

Kunkel, H. G., Simon, H. J., and Fudenberg, H., Arthr. and Rheum. $1958,1,289$.

- Kaplan, H., and Klatskin, G., Yale Ұ. Biol. Med., 1960, 32, 335.
} 
of the erythema nodosum syndrome and the arthritis of synovial sarcoid infiltration may precede the signs of illness elsewhere. Rheumatic fever, rheumatoid arthritis, and even of gout may be suggested diagnoses in this early phase and may on occasion be supported by nonspecific $T$-wave changes in the electrocardiogram ${ }^{6}$ or by positive tests for rheumatoid factor due to gammaglobulin changes $^{7}$ or by elevation of the serum level of uric $\mathrm{acid}^{8}$ due to increased cell division. Isolated case reports have probably overemphasized the importance of these instances of clinical overlap. Gumpel and his colleagues did not find that they were of much importance in practice.

\section{Investigation of the Young Hypertensive}

Despite intensive research into the aetiology of hypertension during the last two decades it is still unhappily true that only in some $10 \%$ of all hypertensive patients is it possible to identify a likely cause for their disease. Further, only in perhaps one-third of this $10 \%$ is it possible to cure or improve the hypertension by an operation on the kidney or adrenal glands. Nearly ten years ago Lord Platt ${ }^{1}$ observed that the incidence of secondary hypertension was relatively high in patients under the age of 40 (in whom he reckoned only about $30 \%$ had primary or " essential" hypertension). Since then most physicians have adopted a conservative attitude to the investigation of hypertensive patients over the age of 40 but have continued to investigate their younger patients intensively. Everyone who does this has the occasional gratifying experience of curing a young hypertensive, but against every patient cured of his hypertension must be set the morbidity of renal investigations, especially aortography ${ }^{2}$ and divided function studies, in the less fortunate remainder. As hypotensive drugs year by year become more effective and produce fewer side-effects the burden of lifelong treatment lessens and the necessity for surgical cure becomes less imperative.

From the Royal Postgraduate Medical School, A. Breckenridge and his colleagues ${ }^{3}$ have just reviewed their experiences in investigating intensively 229 hypertensive patients aged between 12 and 40 . The balance sheet they have drawn up is instructive. Despite investigation as intensive as could reasonably be performed in such a group in only 73 patients (32\%) was a possible cause for hypertension found. In addition there were a further 40 patients not subjected to intravenous pyelography because their renal failure was too severe when first seen or because they died before the investigation could be done. Of the 73 patients in whom a secondary cause of hypertension was suspected only nine were thought suitable for surgical treatment. Nephrectomy was carried out on six patients for renal artery lesions or unilateral pyelonephritis, and in the other three patients the adrenal gland was explored or a renal capsulectomy done. In only three cases was the treatment successful in that no further drug treatment was needed.

Three cures in 229 patients-it is not an encouraging record. A curious feature of the series is that there were so few patients with disease of the main renal artery (only 12 material lesions were identified), and none of these patients

' Platt, R., Quart:' F. Med., 1948, 17, 83.

2 Chamberlain, M. J., and Gleeson, J. A., Lancet, 1965, 1, 619. Breckenridge, A., Preger, L., Dollery, C. T., and Laws, J. W., Quart. F.
Med., 1967, 36, 549 is recorded as having had reconstructive renal artery surgery. The low incidence of disease of the renal artery would be met with amazement bordering on disbelief by American surgeons at Houston and at the Cleveland Clinic, who see a highly selected population. However, even those patients referred to the hypertensive clinic of Hammersmith Hospital are themselves probably a selected group, and it may well be that in a completely unselected population of young hypertensives the true incidence of remediable secondary hypertension is still less than in the Hammersmith series.

Breckenridge and his colleagues point out the moral: that youth alone is an insufficient recommendation for extensive investigation, especially aortography, in the hypertensive patient. Since by far the commonest renal lesion in these young hypertensive patients was chronic pyelonephritis, which could usually be diagnosed by the intravenous pyelogram and by examination of the urine, it seems that aortography or divided function studies can be therapeutically justified only under special circumstances. Patients suitable for intensive investigation are those with a loud renal artery bruit to whom surgery can be offered and by whom it might be accepted, and possibly also those who prove unduly resistant to drug therapy, those who find drug side-effects intolerable, or those whose occupation or domicile makes adequate supervision of their therapy impossible.

Young hypertensive patients should certainly not be denied the benefits of intravenous pyelography, urinalysis, screening of blood electrolytes to detect primary hyperaldosteronism, and, if possible, screening of the urine to detect phaeochromocytoma. These tests are simple, safe, and reasonably inexpensive in time and money. Except under special circumstances investigation should stop at this point, and the patient should be treated with hypotensive drugs unless the reasons for proceeding further are unusually compelling.

\section{Intensive Care}

The value of intensive care units in hospitals has become generally recognized in Britain only in the last five years. As the equipment used in the management of patients with severe cardio-respiratory illness has become more complex so has special training and experience become necessary for those looking after the patients. The best use of men and machines can be made if they are concentrated into one unit and patients who need specialized treatment or monitoring are admitted to it. ${ }^{1}$

Few units in Britain have been working for more than a year or two, but there is now widespread interest in their establishment. In 1962 the Ministry of Health gave its blessing $^{2}$ to hospitals wishing to set up units; now the B.M.A. Planning Unit has issued a useful report ${ }^{3}$ by a working party under the chairmanship of E. J. Moran Campbell which gives advice on the form that units should take, based on the experience of 17 hospitals in the British Isles. This is the first publication from the Planning Unit, and Professor Henry Miller, its director, stresses that the report is in no sense a statement of B.M.A. policy but is an informed assessment of

Brit. med. F., 1966, 2, 1609.

2 Mth. Bull. Minist. Hlth Lab. Serv., 1962, 21, 218

3 Intensive Care, B.M.A. Planning Unit Report No. 1, 1967, B.M.A Price 3s. 6d.

- Organization of Medical Work in the Hospital Service in Scotland, 1967. H.M.S.O. First Report of the foint Working Party on the Organization of Medical
Work in Hospitals, 1967. H.M.S.O.

- Lord Platt, Brit. med. F., 1967, 4, 439. 